Flow and Permeability Evolution During Microbial Sulfate Reduction and Inhibition in Fractured Rocks

Yiwei Cheng ${ }^{1 *}$, Chunwei Chou ${ }^{1}$, Marco Voltolini ${ }^{1}$, Sharon Borglin ${ }^{1}$, Jonathan B. AjoFranklin², Yuxin $\mathrm{Wu}^{1}$

${ }^{1}$ Earth and Environmental Sciences Area, Lawrence Berkeley National Laboratory, Berkeley, CA, USA

${ }^{2}$ Department of Earth, Environmental and Planetary Sciences, Rice University, Houston, TX, USA

Supporting Information

7 Pages

5 Figures

1 Table 

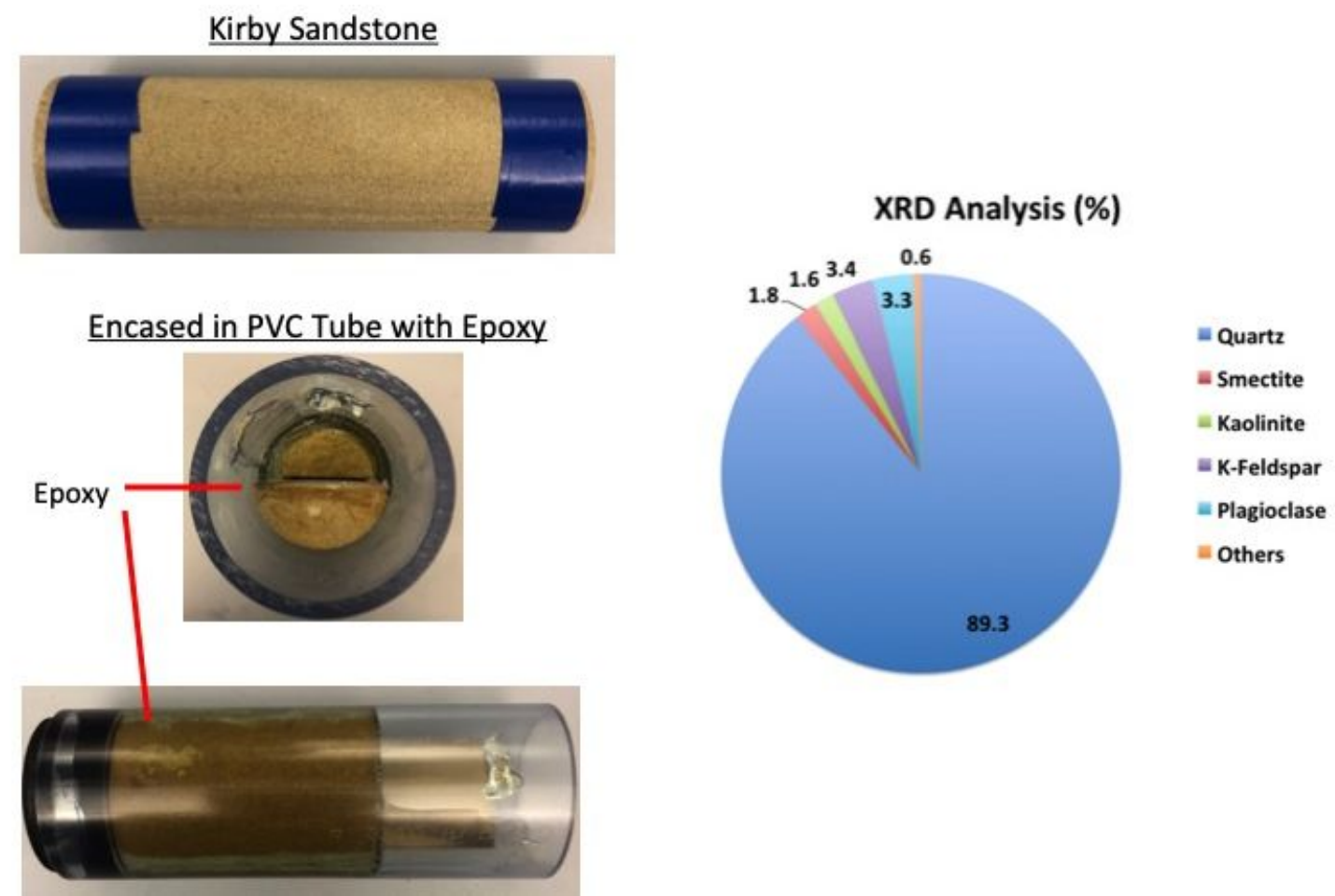

Figure S1: Initial analysis of the kirby sandstone core before the experiment. The sandstone cores were casted with epoxy resin in PVC columns. XRPD (X-Ray Powder Diffraction) Rietveld analysis on the Kirby sandstone revealed mineralogy dominated by quartz, with feldspars and clays compose most of the remaining minerals. 


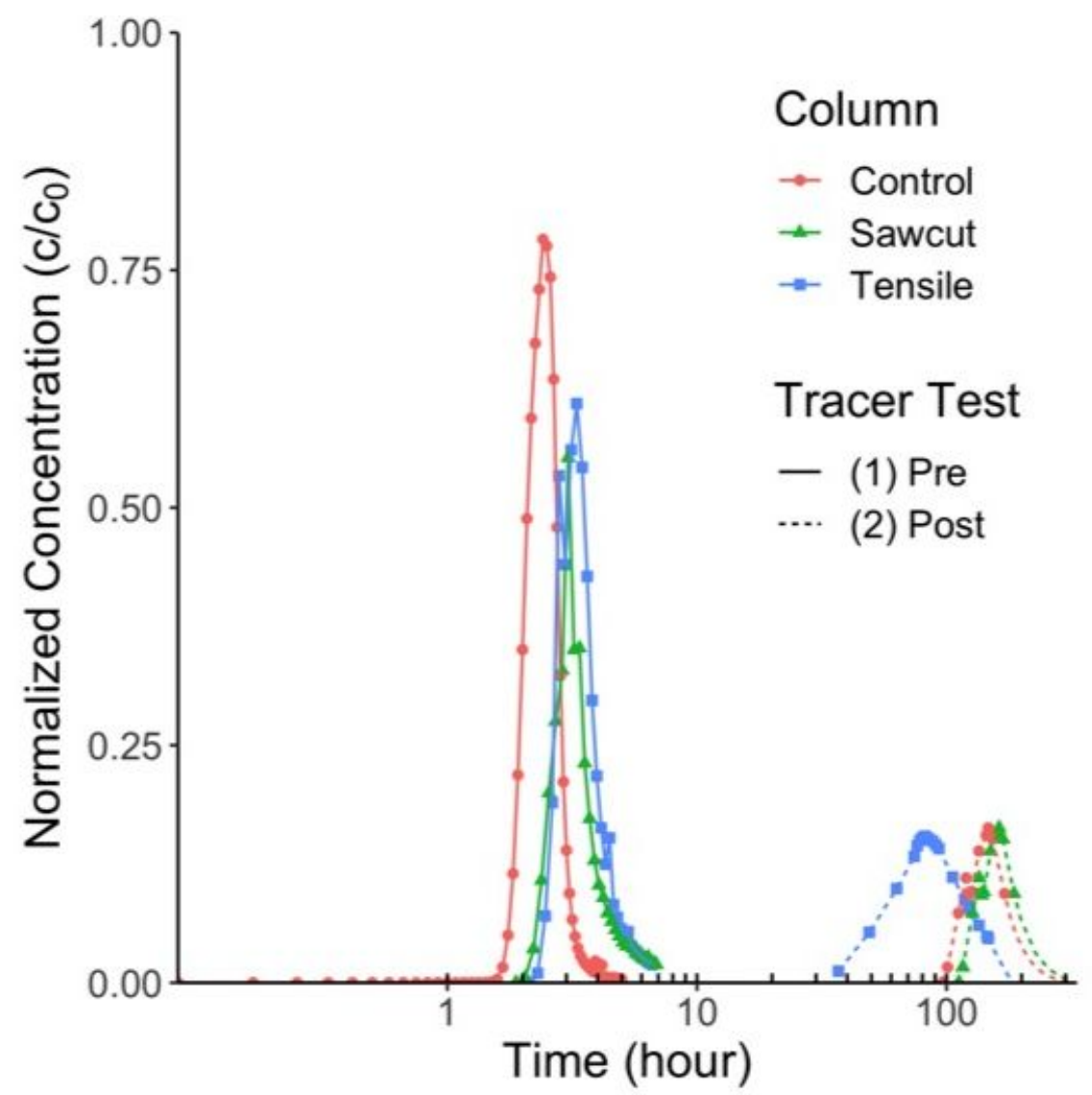

Figure S2: Pre- and post-experiment tracer breakthrough curves. 
Initial Stage

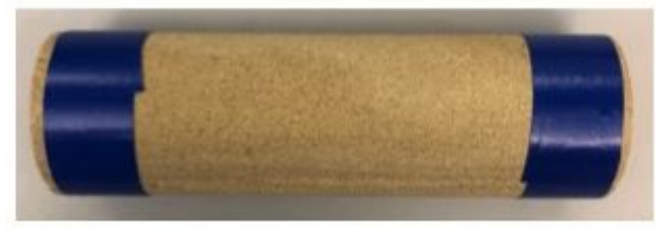

\section{Sawcut Fracture}

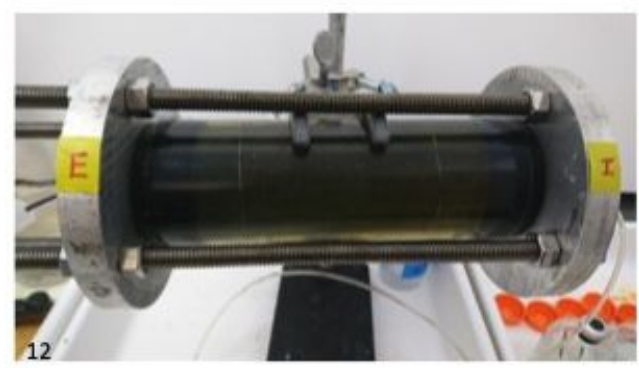

Tensile Fracture

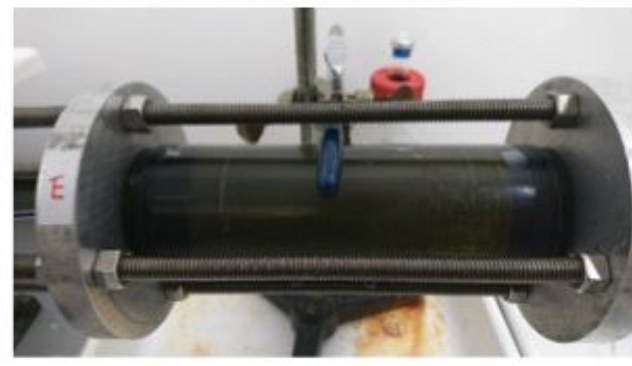

No Fracture

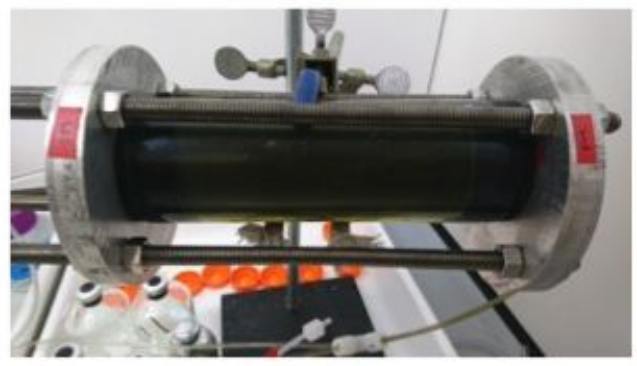

Figure S3: Visible blackening of the column peripherals as of day 60 . 


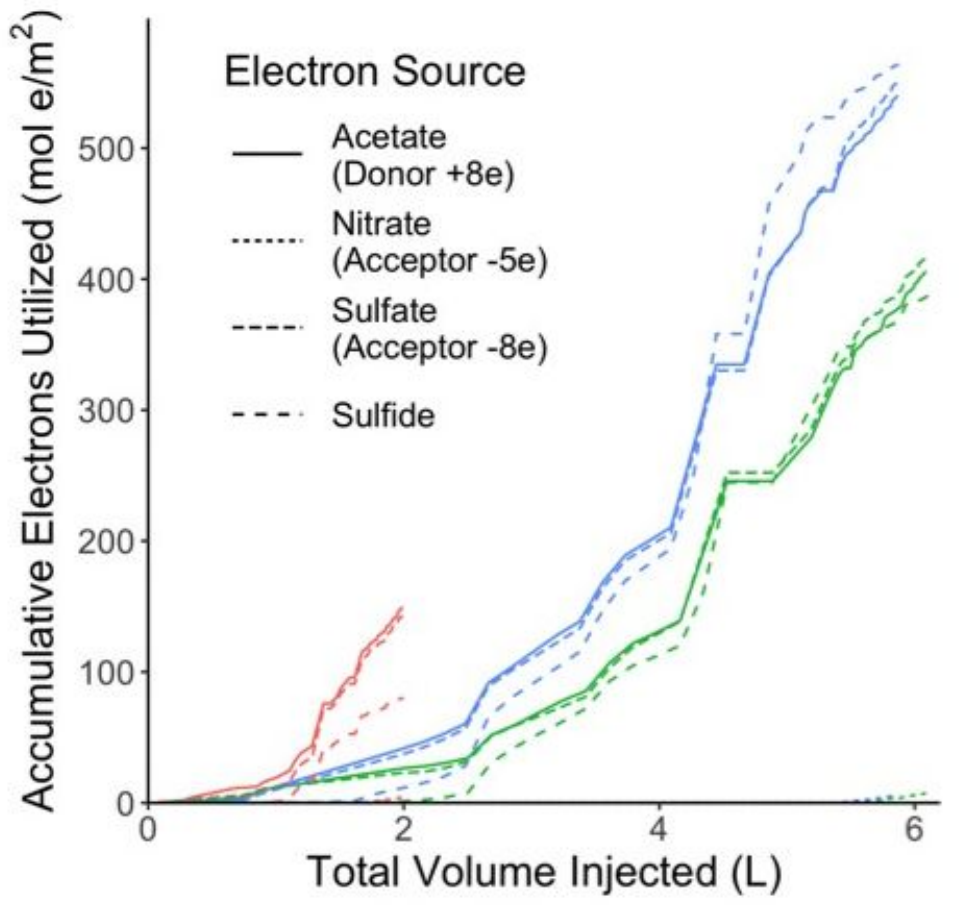

Figure S4: Accumulative amount of electrons utilized in the perspective of the volume of injected fluid. 


\section{Sawcut}

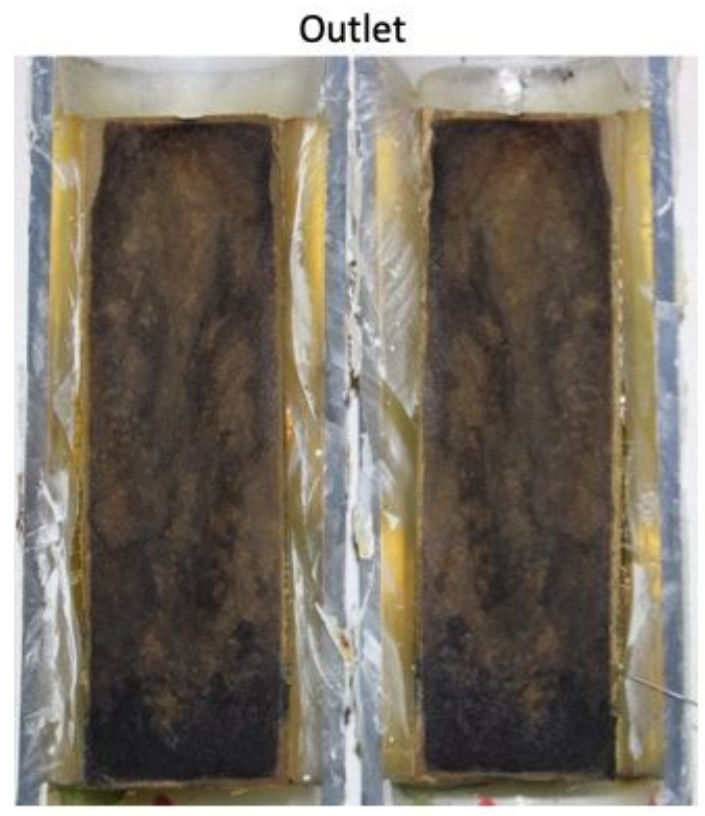

Inlet
Tensile

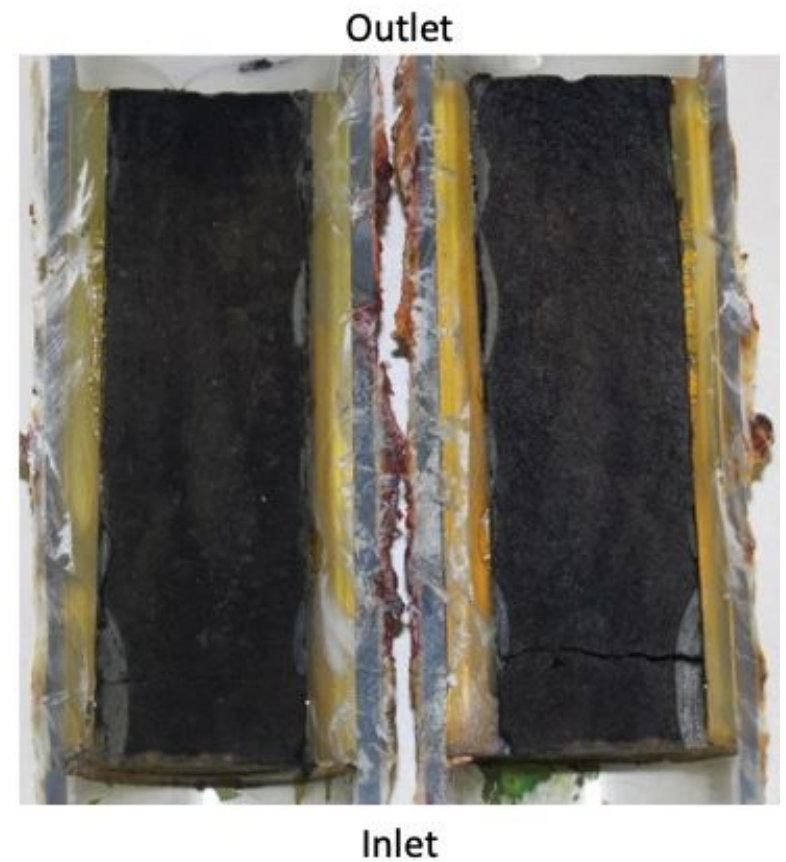

Figure S5. Post experiments, the fractured columns (sawcut and tensile) were split along the fractures. Fracture surfaces for the sawcut column are shown on the left, while fracture surfaces for the tensile column are shown on the right. 
Table S1: Trace minerals in media.

\begin{tabular}{|l|}
\hline \multicolumn{1}{|c|}{ Components } \\
\hline $\mathrm{NTA}$ Disodium Salt \\
\hline $\mathrm{MgSO} 4 \cdot 7 \mathrm{H} 2 \mathrm{O}$ \\
\hline $\mathrm{MnSO} 4 \cdot \mathrm{H} 2 \mathrm{O}$ \\
\hline $\mathrm{NaCl}$ \\
\hline $\mathrm{FeSO} 4 \cdot 7 \mathrm{H} 2 \mathrm{O}$ \\
\hline $\mathrm{CaCl} 2 \cdot 2 \mathrm{H} 2 \mathrm{O}$ \\
\hline $\mathrm{CoCl} 2 \cdot 6 \mathrm{H} 2 \mathrm{O}$ \\
\hline $\mathrm{ZnCl} 2$ \\
\hline $\mathrm{CuSO} 4 \cdot 5 \mathrm{H} 2 \mathrm{O}$ \\
\hline $\mathrm{AlK}(\mathrm{SO} 4) 2 \cdot 12 \mathrm{H} 2 \mathrm{O}$ \\
\hline $\mathrm{Boric} \mathrm{Acid}$ \\
\hline $\mathrm{Na} 2 \mathrm{MoO} 4 \cdot 2 \mathrm{H} 2 \mathrm{O}$ \\
\hline $\mathrm{NiCl} 2 \cdot 6 \mathrm{H} 2 \mathrm{O}$ \\
\hline $\mathrm{Na} 2 \mathrm{WO} 4 \cdot 2 \mathrm{H} 2 \mathrm{O}$ \\
\hline $\mathrm{Na} 2 \mathrm{SeO} 4$ \\
\hline
\end{tabular}

